\title{
The association between Acute Lymphoblastic Leukemia in children and Helicobacter pylori as the marker for sanitation
}

Pengiran Hishamuddin ${ }^{*}$

\begin{abstract}
Background: Greaves "delayed infection" hypothesis suggested that Acute Lymphoblastic Leukemia (ALL) in children is caused by a lack of exposure to infection in infancy, which may be due higher standards of sanitation. We have conducted an ecologic analysis of the relationship between sanitation, using Helicobacter pylori (H. pylori) as the marker, and the incidence of childhood ALL in 127 cancer registries from 28 countries.

Results: There were inverse associations between $H$. pylori prevalence and ALL incidence rates in children. These associations were minor and only significant for ALL incidence rates for all cancer registries. They became non-significant and smaller in magnitude when the population source and/or the GNP per capita were added to the relationship. Furthermore, these results were unchanged when the associations were examined using the Generalized Estimating Equations.

Conclusions: Although the findings showed lower prevalence of H. pylori and improved sanitation is associated with increased incidence of childhood ALL, they do not conclusively support Greaves "delayed infection" hypothesis.
\end{abstract}

Keywords: Public health, Epidemiology, Oncology

\section{Background}

Leukemia is the most common cancer in children [1]. The major types of childhood leukemia are acute lymphoblastic leukemia (ALL) and acute myeloid leukemia (AML) [1,2]. ALL accounts for the majority of childhood leukemia [1,2]. The incidence of childhood ALL has increased over the past 20 years [1,2]. This trend is more apparent among 2 to 5 years and in developed countries [1-3].

Genetic alterations occurring during fetal development increase the risk of childhood ALL $[4,5]$. However, these genetic factors are insufficient for leukemogenesis, which appears to require a "second hit" [6]. One potential mechanisms of such "second hit" transition is proposed by the "delayed infection" (or Greaves) hypothesis [7]. According to the Greaves' hypothesis, ALL in children is caused by a lack of exposure to infections in infancy.

Correspondence: hishamuddin_badaruddin@moh.gov.sg

Surveillance and Response Branch, Communicable Diseases Division, Ministry of Health, 16 College Road, Singapore 169854, Republic of Singapore
This inadequate exposure to infections in infancy leads to failure of modulation in the immune system, which involves changes to certain T-cells [7]. Exposure to one or more common bacterial or viral infections later in life, for example after mixing with carriers such as children in playgroups or schools $[8,9]$, then results in an abnormal immune response and eventually ALL. This delayed infection may be due to improved sanitary conditions found in modern lifestyles [7]. Greaves' "delayed infection" hypothesis is conceptually similar to the "hygiene hypothesis" that has been proposed to explain allergies, asthma and type 1 diabetes [10]. The "hygiene hypothesis" suggests that early childhood infections are needed to promote the development of the immune system and to suppress allergic and autoimmune disorders.

This study examines Greaves' "delayed infection" hypothesis by looking at whether level of sanitation is associated with the incidence rates of childhood ALL in different countries. In this study we use Helicobacter pylori (H. pylori) as a marker of sanitation. H. pylori is an ubiquitous bacterium affecting a large percentage of the 
world's population [11]. Prevalence of $H$. pylori is greater in people who reside in conditions with inadequate saniation [12]. Therefore, lower prevalence of $H$. pylori is associated with improved sanitation and lack of exposure to infections. Under the "delayed infection" hypothesis countries with lower prevalence of $H$. pylori are expected to have a higher incidence rate of childhood ALL and vice versa.

\section{Methods}

\section{ALL incidence rates}

The ALL incidence rates (per 100, 000 persons) in 0 to 4 years old children obtained from the monograph, Cancer Incidence in Five Continents, Volume VIII, published jointly by the International Agency for Research on Cancer (IARC) and the International Association of Cancer Registries (IARC) [13]. Data were available from 185 cancer registries in 56 countries. However, the analyses were confined to those countries in which corresponding H. pylori prevalence rates for children were available. These comprised 28 countries that include 127 cancer registries. All the data were collected between 1991 and 1998, with the majority (78\%) collected between 1993 and 1997.

\section{Weighted ALL incidence rates}

Weighted ALL incidence rates, which is the pooled estimate of the ALL incidence rates for cancer registries in a country, were calculated using the inverse variance method where larger studies are given more weight than smaller studies [14]. If $\mathrm{I}_{\mathrm{i}},(\mathrm{i}=1,2 \ldots)$, is the ALL incidence rate for the $i^{\text {th }}$ cancer registry in a country, then the weighted ALL incidence rate for the entire country is defined as $\left(\sum \mathbf{I}_{\mathbf{i}} \mathbf{w}_{\mathbf{i}}\right) /\left(\sum \mathbf{w}_{\mathbf{i}}\right)$, where the registry-specific weight $\left(\mathrm{w}_{\mathrm{i}}\right)$ equals $1 /\left(\mathrm{s}_{\mathrm{i}}^{2}\right)$ and $\mathrm{s}_{\mathrm{i}}^{2}$ represents the variance of the $I_{i}$ estimate. As ALL incidence rates are binomially distributed, the variance $\left(s_{i}^{2}\right)$ for the ALL incidence rate for each individual cancer registry was obtained using the formula $\mathbf{s}_{\mathbf{i}}^{2}=\mathbf{n}_{\mathbf{i}} \mathbf{I}_{\mathbf{i}}\left(\mathbf{1}-\mathbf{I}_{\mathbf{i}}\right)$, where $\mathrm{n}_{\mathrm{i}}(\mathrm{i}=1,2 \ldots)$ is the population size of children aged 0 to 4 years old in the $\mathrm{i}^{\text {th }}$ cancer registry, and $I_{i}(i=1,2 \ldots)$ is the ALL incidence rate for the $\mathrm{i}^{\text {th }}$ cancer registry in a country [15].

\section{H. pylori prevalence rates}

The prevalence rates (per 100 persons) of H. pylori infection in children from 26 countries were obtained from studies reviewed by Torres et al [16]. To supplement these data, a Medline search of articles using the search term Helicobacter pylori and prevalence was conducted and $H$. pylori prevalence rates for two additional countries, Singapore [17] and Thailand [18], were found.

Only one $H$. pylori prevalence rate, for children between 0 to 10 years old was used for each country. The prevalence rates/studies included in the analyses were selected based on the following criteria:
- Studies which looked exclusively at infants aged 0 to 1 years old were excluded, as the H. pylori prevalence in this age group, especially when measured using the serological assays, could be influenced by maternal IgG antibodies that were transferred to the child [16].

- The maximum age of children in the studies was limited to 10 years old as the most relevant group for ALL children is under this age [1-3].

- Studies with children 1 to 4 years old were preferred, and if this was not available then the next youngest age group was selected.

\section{Covariates}

Certain characteristics of the H. pylori studies were considered as potential confounders. All H. pylori surveys were characterized as either clinic-based or populationbased. Clinic-based surveys can be affected by selection bias because participants in these studies may have higher socioeconomic status and live in better sanitary conditions [16]. As a result $H$. pylori prevalence rates are more likely to be lower in clinic-based samples. Another potential confounder was the method of $H$. pylori detection. The studies used either the urea breath test or serological assays of IgG antibodies. The H. pylori prevalence rates differ depending on which method was utilized, and this is due to the different sensitivities and specificities associated with these diagnostic tests [19]. The degree of urbanization in the area where the studies were conducted was also a potential confounder as $H$. pylori prevalence rates have been shown to be higher in more urban areas [16]. The minimum and maximum ages of children in the studies, were considered potential confounders as $H$. pylori prevalence rates and ALL incidence rates are known to change according to age groups [16]. H. pylori prevalence rates also vary according to geographic locations $[16,19]$, and therefore the regional location of a country was considered a potential confounder. To examine this, all countries that provided the data for analyses were categorized according to the World Health Organization (WHO) regions [20]. The data for each country also included the interval between the year of the ALL incidence and the year when the $H$. pylori survey was conducted.

Characteristics of the countries considered in this study included the Gross National Product (GNP) per capita, Human Development Index (HDI) and the population size. GNP per capita is defined as the dollar value of a country's final output of goods and services in a year, divided by its population size [21]. This reflects the average income of a country's citizens. HDI measures a country's average achievements in human development [22]. It consists of three components - life expectancy at birth, 
education levels, and standards of living as measured by the Gross Domestic Product per capita. GNP per capita and HDI are considered to be markers for the level of affluence and development of a country, and also potential confounders for $H$. pylori prevalence and ALL incidence rates. This is because countries with higher GNP per capita and HDI typically have improved levels of sanitation and healthcare, and are likely to have lower $H$. pylori prevalence and higher ALL incidence rates. For each country, the analytic dataset included the GNP per capita and the population size corresponding to the year the H. pylori study [21]. The United Nations Development Program releases HDI data every 5 years [22]. The specific HDI value was selected based in its proximity to the H. pylori survey.

\section{Statistical analyses}

The ALL incidence rates were considered using two methods: the weighted method combined the data from all cancer registries is each country $(n=28)$ and the nonweighted method included data from each cancer registry separately $(\mathrm{n}=127)$. The $H$. pylori prevalence rate was continuously entered into all the models.

The minimum and maximum age of children in the $H$. pylori studies, the interval between the ALL incidence and $H$. pylori surveys, the GNP per capita, the HDI, and the population size were treated as continuous variables. The method of $H$. pylori detection (urea breath test versus serological assay), the population source (clinic-based versus community-based), the level of urbanization (urban, rural or both) and the WHO region (Africa, Americas, South East Asia, Europe and Western Pacific) were treated as categorical variables.

All analyses were performed using the software SAS 9.1.3.

\section{Univariate analyses}

PROC UNIVARIATE was used to look at the normal distributions, mean, median, and standard deviation of all continuous variables. PROC FREQ was used to produce counts and cross tabulation tables for all categorical variables. Both the continuous and categorical variables were examined for missing values and extreme outliers.

Both outcome variables (the weighted ALL incidence rates for each country and the ALL incidence rates for all cancer registries) were normally distributed. Only one other continuous covariate, the interval between ALL incidence and $H$. pylori surveys, was normally distributed. No issues with regards to missing values were found in all the continuous and categorical variables. No problems with extreme outliers were identified in continuous variables.

\section{Bivariate analyses}

All bivariate analyses were performed twice, initially with the weighted ALL incidence rate for each country $(n=28)$ and then repeated with the ALL incidence rate for all cancer registries $(n=127)$ in the model. PROC CORR was used to perform correlations between:

- Both outcome variables and the H. pylori prevalence rates.

- Both outcome variables and the other continuous covariates.

- The H. pylori prevalence rates and the other continuous covariates.

- The other continuous covariates with each other.

The $r^{2}$ value, which denotes the percentage of variation in the dependent outcome variable which is accounted for by the independent exposure variable or covariates, and the significance of the correlation ( $\mathrm{p}$-value of less than 0.05) was looked at. Pearson's method was used to look at the correlation between both outcome variables and the interval between ALL incidence and $H$. pylori surveys. This method was applied as both the outcome variables and this continuous covariate were normally distributed. Spearman's method was used for all other correlations as at least one continuous variable then was not normally distributed. For categorical variables, PROC GLM or PROC ANOVA was performed to look at the mean, standard deviation and significance ( $\mathrm{p}$-value of less than 0.05) of the prevalence of both outcome variables, $H$. pylori prevalence rate, the other continuous and categorical covariates, in each category of the categorical covariates.

\section{Bivariate analyses: the correlations between ALL incidence, $H$. pylori prevalence and characteristics of $H$. pylori studies/ countries $(n=28)$}

The correlations between all continuous variables when the weighted ALL incidence rates for each country $(\mathrm{n}=28)$ were modeled were calculated using PROC CORR. Pearson's method was used for the correlation between the weighted ALL incidence rates for each country and the interval between the ALL incidence and the $H$. pylori surveys, as both these variables were normally distributed. Spearman's method was used for all other correlations as at least one continuous variable then was not normally distributed. The weighted ALL incidence rates for each country was negatively correlated to the $H$. pylori prevalence rates but this was not significant $\left(r^{2}=-0.14, p\right.$-value $\left.=0.48\right)$. The covariates which were not significantly correlated with both the weighted ALL incidence rates for each country and the $H$. pylori prevalence rates were the minimum and maximum age of children in the $H$. pylori studies, the interval between the ALL incidence and the $H$. pylori surveys and the population size of 
the countries. These 4 covariates could potentially be excluded from the model. Significant correlations identifying potential confounders were:

- H. pylori prevalence rates and GNP per capita $\left(\mathrm{r}^{2}=-0.60\right.$, $\mathrm{p}$-value $\left.=0.0007\right)$.

- H. pylori prevalence rates and HDI $\left(\mathrm{r}^{2}=-0.57\right.$, $\mathrm{p}$-value $=0.002$ ).

Significant correlation identifying potential collinearity was:

- GNP per capita and HDI $\left(\mathrm{r}^{2}=0.95, \mathrm{p}\right.$-value $\left.=<0.0001\right)$

Bivariate analyses: the correlations between ALL incidence, H. pylori prevalence and characteristics of $H$. pylori studies/ countries $(n=127)$

The correlations between all continuous variables when the ALL incidence rates for all cancer registries in all countries $(\mathrm{n}=127)$ were modeled were calculated using PROC CORR. Pearson's method was used for the correlations between the ALL incidence rates for all cancer registries in all countries and the interval between the ALL incidence and the $H$. pylori surveys, as both these variables were normally distributed. Spearman's method was used for all other correlations as at least one continuous variable then was not normally distributed. The ALL incidence rates for all cancer registries in all countries was negatively correlated to the H. pylori prevalence rates but this was not significant $\left(\mathrm{r}^{2}=-0.17, \mathrm{p}\right.$-value $\left.=0.05\right)$. The covariates which were not significantly correlated with both the ALL incidence rates for all cancer registries and the $H$. pylori prevalence rates were the maximum age of children in the $H$. pylori studies and the interval between the ALL incidence and the $H$. pylori surveys. These 2 covariates could potentially be excluded from the model.

Significant correlations identifying potential confounders were:

- ALL incidence rates for all cancer registries and GNP per capita $\left(r^{2}=0.38\right.$, $\mathrm{p}$-value $\left.=<0.0001\right)$

- ALL incidence rates for all cancer registries and HDI $\left(\mathrm{r}^{2}=0.41, \mathrm{p}\right.$-value $\left.=<0.0001\right)$

- ALL incidence rates for all cancer registries and population size of countries $\left(\mathrm{r}^{2}=-0.21\right.$, $\mathrm{p}$-value $\left.=0.019\right)$.

- H. pylori prevalence rates and GNP per capita $\left(\mathrm{r}^{2}=-0.43\right.$, $\mathrm{p}$-value $\left.=<0.0001\right)$.

- H. pylori prevalence rates and the HDI $\left(\mathrm{r}^{2}=-0.40\right.$, p-value $=<0.0001)$.

- H. pylori prevalence rates and the population size of countries $\left(\mathrm{r}^{2}=0.54\right.$, $\mathrm{p}$-value $\left.=<0.0001\right)$.

- H. pylori prevalence rates and the minimum age of children in the H. pylori studies $\left(\mathrm{r}^{2}=0.24\right.$, $\mathrm{p}$-value $=0.003)$.
Significant correlations identifying potential collinearity were:

- GNP per capita and the HDI (r2=0.97, $\mathrm{p}$-value $=<0.0001)$.

- GNP per capita and population size ( $\mathrm{r} 2=-0.25$, p-value $=0.005$ ).

- HDI and population size of countries ( $\mathrm{r} 2=-0.26$, $\mathrm{p}$-value $=0.003)$.

Bivariate analyses: the relation of ALL incidence, $H$. pylori prevalence, the minimum and maximum age of children, the interval between ALL incidence and $H$. pylori surveys, GNP per capita, HDI and population size to various characteristics of $H$. pylori studies $(n=28)$

PROC GLM was performed to look at the mean, standard deviation and significance (p-value of less than 0.05) of the prevalence of the weighted ALL incidence rates for each country, the $H$. pylori prevalence rates and the other continuous covariates, in each category of the categorical covariates (which were certain characteristics of the $H$. pylori studies). The prevalence of both the weighted ALL incidence rates for each country and the $H$. pylori prevalence rates was not significant in the method of $H$. pylori used in the $H$. pylori studies. This covariate could potentially be excluded from the model.

Significant associations identifying potential confounders were:

- The prevalence of $H$. pylori prevalence rates in the population source used in the $H$. pylori survey $(\mathrm{p}=0.04)$, the level of urbanization in the $H$. pylori studies $(p=0.02)$ and the region a country is situated $(\mathrm{p}=0.0003)$.

Significant associations identifying potential collinearity were:

- The prevalence of GNP per capita in the level of urbanization in the $H$. pylori studies $(\mathrm{p}=0.02)$.

- The prevalence of HDI in the level of urbanization in the $H$. pylori studies $(\mathrm{p}=0.008)$ and the region a country is situated $(\mathrm{p}=<0.0001)$.

Bivariate analyses: the relation of ALL incidence, $H$. pylori prevalence, the minimum and maximum age of children, the interval between ALL incidence and $H$. pylori surveys, GNP per capita, $\mathrm{HDI}$ and population size to various characteristics of H. pylori studies $(n=127)$

PROC GLM were performed to look at the mean, standard deviation and significance (p-value of less than 0.05) of the prevalence of the ALL incidence rates for all cancer registries, the $H$. pylori prevalence rates and the other continuous covariates, in each category of the 
categorical covariates (which were certain characteristics of the H. pylori studies). The prevalence of both the ALL incidence rates for all cancer registries and the $H$. pylori prevalence rates was not significant in the method of $H$. pylori detection used in the $H$. pylori studies. This covariate could potentially be excluded from the model.

Significant associations identifying potential confounders were:

- The prevalence of the ALL incidence rates for all cancer registries in the population source used in the H. pylori survey $(\mathrm{p}=0.038)$, the level of urbanization in the H. pylori studies $(\mathrm{p}=0.002)$ and the region a country is situated $(\mathrm{p}=0.0008)$.

- The prevalence of $H$. pylori prevalence rates in the population source used in the H. pylori survey $(\mathrm{p}=<0.0001)$, the level of urbanization in the H. pylori studies $(\mathrm{p}=<0.0001)$ and the region a country is situated $(\mathrm{p}=<0.0001)$.

Significant associations identifying potential collinearity were:

- The prevalence of GNP per capita in the level of urbanization in the H. pylori studies $(\mathrm{p}=<0.0001)$ and the region a country is situated $(\mathrm{p}=<0.0001)$.

- The prevalence of HDI in the population source used in the H. pylori survey ( $\mathrm{p}=0.004)$, the level of urbanization in the $H$. pylori studies $(\mathrm{p}=<0.0001)$ and the region a country is situated $(\mathrm{p}=<0.0001)$.

- The prevalence of the population size of countries in the population source used in the H. pylori survey ( $\mathrm{p}=0.0006)$, the level of urbanization in the H. pylori studies $(\mathrm{p}=<0.0001)$ and the region a country is situated $(\mathrm{p}=<0.0001)$.

\section{Bivariate analyses: the associations among various characteristics of $\mathrm{H}$. pylori studies $(n=28)$}

PROC ANOVA were performed to look at the mean, standard deviation and significance ( $\mathrm{p}$-value of less than o.05) of the prevalence of the categorical covariates in each other, when the weighted ALL incidence rates in each country was modeled.

Significant associations identifying potential collinearity was:

- The prevalence of the population source used in the $H$. pylori survey in the level of urbanization in the H. pylori studies $(\mathrm{p}=0.007)$.

\section{Bivariate analyses: the associations among various} characteristics of $H$. pylori studies $(n=127)$

PROC ANOVA were performed to look at the mean, standard deviation and significance ( $\mathrm{p}$-value of less than
0.05) of the prevalence of the categorical covariates in each other, when the ALL incidence rates in all cancer registries were modeled.

Significant associations identifying potential collinearity were:

- The population source used in the H. pylori survey in the level of urbanization in the H. pylori studies $(\mathrm{p}=<0.0001)$.

- The level of urbanization in the H. pylori studies in the population source used in the H. pylori survey $(\mathrm{p}=0.002)$ and the region a country is situated $(\mathrm{p}=<0.0001)$.

\section{Covariates or confounders excluded from further analyses}

Covariates which were not correlated or associated with either $H$. pylori prevalence of ALL incidence rates were not included in the model. The confounders that remained were examined for collinearity. When this existed one confounder was chosen to be included in the model based on the strength of its correlation or association to either $H$. pylori prevalence or ALL incidence rates.

\section{Continuous covariates or confounders excluded from further analyses}

GNP per capita and the HDI were positively correlated with ALL incidence rates. This correlation was not significant when weighted ALL incidence rates were modeled (GNP per capita: $\mathrm{r}^{2}=0.22, \mathrm{p}$-value $=0.26$; HDI: $r^{2}=0.18, p$-value $\left.=0.36\right)$ but was significant when the ALL incidence rates for all cancer registries were modeled (GNP per capita: $\mathrm{r}^{2}=0.38$, $\mathrm{p}$-value $=<0.0001$; HDI: $\mathrm{r}^{2}=0.41$, p-value $\left.=<0.0001\right)$. GNP per capita and the HDI were negatively correlated with the $H$. pylori prevalence rates. For example, when the ALL incidence rates for all cancer registries were used as the outcome variable, the correlation between $H$. pylori prevalence rates and GNP per capita had a $\mathrm{r}^{2}$ of -0.43 and a p-value of $<0.0001$ whereas the correlation between $H$. pylori prevalence rates and HDI had a $\mathrm{r}^{2}$ of -0.40 and a p-value of $<0.0001$. GNP per capita and HDI were highly correlated to each other. For example, when the weighted ALL incidence rates for each country were used in the model, the correlation between these two was significantly positive with a $\mathrm{r}^{2}$ of 0.95 and a $\mathrm{p}$-value of $<0.0001$. This meant that both covariates could not be considered in the same model as doing so might lead to potential collinearity. GNP per capita was the covariate used in the further analyses based on its higher correlation to the $H$. pylori prevalence and ALL incidence rates.

The population size of the countries was negatively correlated with the ALL incidence rates. This correlation was 
significant when the ALL incidence rates for all cancer registries were modeled $\left(r^{2}=-0.21, p\right.$-value $\left.=0.019\right)$. The population size of countries was positively correlated with the $H$. pylori prevalence rates. This correlation was significant when the outcome variable was the ALL incidence rates in all cancer registries $\left(r^{2}=0.54, p\right.$-value $\left.=<0.0001\right)$. The population size of a country was negatively correlated with a confounder, GNP per capita. This correlation was significant when the ALL incidence rates for all cancer registries were modeled $\left(r^{2}=-0.25, p\right.$-value $\left.=0.005\right)$. This is not surprising as the denominator in the calculation of the GNP per capita of a country is its population size. The population size of a country was therefore excluded from further analysis.

The minimum age of children in the $H$. pylori studies was positively correlated with the $H$. pylori prevalence rates. This correlation was significant when the outcome variable was the ALL incidence rates for all cancer registries $\left(\mathrm{r}^{2}=0.24, \mathrm{p}\right.$-value $\left.=0.003\right)$. This covariate was not consistently correlated with both ALL incidence rates. When the weighted ALL incidence rates for each country were modeled, the correlation had a $\mathrm{r}^{2}$ of 0.34 with a p-value of 0.08 and when the ALL incidence rates for all cancer registries were modeled, the correlation had a $\mathrm{r}^{2}$ of -0.008 with a p-value of 0.93 . Therefore, the minimum age of children in the $H$. pylori studies was excluded from further analysis.

The maximum age of children in the $H$. pylori studies was not consistently correlated with both ALL incidence rates. When the weighted ALL incidence rates for each country were modeled, the correlation had a r2 of -0.23 with a p-value of 0.24 and when the ALL incidence rates for all cancer registries were modeled, the correlation had a r2 of 0.10 with a p-value of 0.29 . This covariate was also not consistently correlated with the $H$. pylori prevalence rates. When the weighted ALL incidence rates for each country were modeled, the correlation with the $H$. pylori prevalence rates had a $\mathrm{r}^{2}$ of 0.24 with a $\mathrm{p}$-value of 0.21 and when the ALL incidence rates for all cancer registries were modeled, the correlation with the $H$. pylori prevalence rates had a $\mathrm{r}^{2}$ of -0.08 with a $\mathrm{p}$-value of 0.38 . Therefore, the maximum age of children in the $H$. pylori studies was not used in the further analysis.

The interval between the ALL incidence and the H. pylori surveys was not consistently correlated with both ALL incidence rates. When the weighted ALL incidence rates for each country were modeled, the correlation had a $\mathrm{r}^{2}$ of 0.21 with a p-value of 0.27 and when the ALL incidence rates for all cancer registries were modeled, the correlations had a $\mathrm{r} 2$ of -0.15 with a p-value of 0.08 . The interval between the ALL incidence and the $H$. pylori surveys was not consistently correlated with the $H$. pylori prevalence rates. When the weighted ALL incidence rates for each country were modeled, the correlation with the $H$. pylori prevalence rates had a $\mathrm{r}^{2}$ of -0.01 with a p-value of 0.94 and when the outcome variable was the ALL incidence rates for all cancer registries, the correlation with the $H$. pylori prevalence rates had a $\mathrm{r}^{2}$ of -0.009 with a p-value of 0.92 . Therefore the interval between the ALL incidence and the H. pylori surveys was not used in the further analysis. This meant that the only continuous confounder in the model was GNP per capita.

\section{Categorical covariates or confounders excluded from further analyses}

The method of H. pylori detection used in the H. pylori studies was not associated with $H$. pylori prevalence for both ALL incidence rates. For example when the weighted ALL incident rates for each country were modeled, the association between the method of $H$. pylori detection used in the $H$. pylori studies and the $H$. pylori prevalence rates had a p-value of 0.14 and between the method of $H$. pylori detection used in the $H$. pylori studies and ALL incidence rates had a p-value of 0.08. This covariate was therefore excluded from further analysis.

The population source used in the $H$. pylori survey was associated with ALL incidence rates for all cancer registries $(\mathrm{p}$-value $=0.038)$. The type of population source used in the $H$. pylori survey was also associated H. pylori prevalence rates for both outcomes. For example, when the ALL incidence rates for all cancer registries were modeled, the associations between the population source used in the $H$. pylori survey and $H$. pylori prevalence rates had a $\mathrm{p}$-value of $<0.0001$.

The level of urbanization in the $H$. pylori studies was associated with ALL incidence rates for all cancer registries ( $\mathrm{p}$-value $=0.002)$. The level of urbanization in the $H$. pylori studies was also associated with $H$. pylori prevalence rates for both outcomes. For example, when the ALL incidence rate for all cancer registries were modeled, the association between level of urbanization in the $H$. pylori studies and the $H$. pylori prevalence rates had a p-value of $<0.0001$.

The region each country was situated in was associated with ALL incidence rates for all cancer registries ( $\mathrm{p}$-value $=0.0008)$. The region each country was situated in was also associated $H$. pylori prevalence rates for both outcomes. For example, when the ALL incidence rates for all cancer registries were modeled, the association between region each country was situated in and $H$. pylori prevalence rates had a p-value of $<0.0001$.

The level of urbanization in the $H$. pylori studies and the region each country was situated in were associated with GNP per capita. For example when the ALL incidence rates for all cancer registries were modeled, the association between GNP per capita and the level of urbanization in the $H$. pylori studies and between GNP per capita and the region in each country was situated both had a p-value of $<0.0001$. The level of urbanization 
in the $H$. pylori studies and the region each country was situated in were excluded from further analyses as GNP per capita had a higher correlation to the $H$. pylori prevalence and ALL incidence rates.

\section{Confounders included in further analyses}

Therefore, confounders that remained and which did not have collinearity with each other, were GNP per capita (continuous) and the population source used in the $H$. pylori survey (clinic-based or community-based samples). These two confounders were included in the final analyses.

\section{Linear regression - unadjusted and adjusted analyses}

The population source used in the $H$. pylori survey was analyzed using a new categorical covariate (population1) which was created using dummy variables, where the reference group is community-based population samples. PROC REG was used to perform unadjusted linear regression analyses between the outcome variables and the $H$. pylori prevalence rates, and the confounders the GNP per capita and the population source used in the $H$. pylori survey. PROC REG was then repeated to perform adjusted linear regression analyses between the outcome variables and the $H$. pylori prevalence rates, controlling for both confounders separately, and then simultaneously. For each step of the analyses the parameter estimate (coefficient), standard error and significance ( $p$-value of less than 0.05) was looked at. All linear regression analyses were performed twice, initially with the weighted ALL incidence rates for each country $(n=28)$ as the outcome variable and then repeated with the ALL incidence rates for all the cancer registries $(\mathrm{n}=127)$.

\section{Generalized Estimating Equations}

Generalized Estimating Equations (GEE) [14], were used to assess the relationship between $H$. pylori prevalence and ALL incidence rates among the 127 cancer registries in the 28 countries, accounting for the dependency and repeated observations within countries. PROC GENMOD was used to perform unadjusted analyses between the outcome variable (which in this method is the ALL incidence rates in all cancer registries belonging to the same country) and the $H$. pylori prevalence rates, and the confounders - the GNP per capita and the population source used in the $H$. pylori survey. PROC GENMOD was then repeated to perform adjusted analyses between the outcome variable and the $H$. pylori prevalence rates, controlling for both confounders separately and then simultaneously. For each step of the analyses the parameter estimate (coefficient), standard error and significance (p-value of less than 0.05) was looked at.

\section{Regression diagnostics}

The assumptions (that there is a linear relationship between the outcome and predictor variables and that the errors are independent and normally distributed with a mean of 0 and $\sigma^{2}$ ) of the linear regression models were examined by plotting:

- The values of the outcome variable against its predicted values. This plot should look like a $45^{\circ}$ line when the $\mathrm{X}$ and $\mathrm{Y}$ axes are scaled the same.

- The studentized residuals against the predicted values for the outcome variable. If the assumption for the constant variance of errors is true then this plot should show a random scatter about 0 and the width of the scatter should be the same.

- The studentized residuals against the values of the predictor variables. If the assumption for the constant variance of errors is true then this plot should show a random scatter about 0 and the width of the scatter should be the same. This plot was done for each predictor variable in the model.

- Normal probability plot of errors. This checks the normality assumption.

In addition, issues with regards to influential outliers and collinearity were addressed. The assumptions for the linear regression models were met and there were no issues with regards to influential outliers and collinearity.

\section{Ethical approval}

As this study was an ecological study which utilized previously published data and which was not research involving human subjects or animals, it required no submission to IRB. This was determined in consultation with the Communicable Diseases Division, Ministry of Health, Singapore.

\section{Results and discussion}

The characteristics of the H. pylori studies are shown in Table 1. These together with characteristics of countries included in the analyses are described further in Table 2. Weighted ALL incidence rates for each country $(n=28)$ had a median of 16.40 per 100, 000 persons (standard deviation $=11.75$ ) as compared to the ALL incidence rates for all cancer registries $(n=127)$ which had a median of 21.25 per 100,000 persons (standard deviation = 12.62). As for the $H$. pylori prevalence (\%), this ranged from $3 \%$ to $74 \%$ and had a median of $19.30 \%$. The children included in the $H$. pylori studies, had a median minimum age of 1.50 years (standard deviation $=2.25$ years), and a median maximum age of 5.00 years (standard deviation $=2.43$ years). There were more studies using serological assays $(n=25)$ than urea breath test 
Table 1 Characteristics of $\boldsymbol{H}$. pylori studies

\begin{tabular}{|c|c|c|c|c|c|c|c|c|c|c|}
\hline Country & $\begin{array}{l}\text { H. pylori } \\
\text { prevalence }^{a}\end{array}$ & $\begin{array}{l}\text { Min. }_{\text {age }} \\
\text { b }\end{array}$ & $\begin{array}{l}\text { Max. } \\
\text { age }^{c}\end{array}$ & No. $^{d}$ & Method $^{f}$ & $\begin{array}{l}\text { Population } \\
\text { source }^{\mathrm{g}}\end{array}$ & $\begin{array}{l}\text { Level of } \\
\text { urbanization }^{\mathrm{h}}\end{array}$ & Year & Region $^{k}$ & Reference \\
\hline Algeria & 45 & 0 & 9 & 42 & Serology & Clinic & Urban & 1987 & Africa & Megraud et al. [23] \\
\hline Brazil & 36.7 & 3 & 5 & 60 & Serology & Clinic & Urban & 1992 & Americas & Oliveira et al. [24] \\
\hline Colombia & 61 & 2 & 5 & 373 & UBT & Community & Rural & 1992 & Americas & Goodman et al. [25] \\
\hline Costa Rica & 60 & 7 & 10 & 60 & Serology & Community & Rural & 1984-1988 & Americas & Sierra et al. [26] \\
\hline USA & 35 & 1 & 5 & 182 & Serology & Clinic & Both & 1998 & Americas & Elitsur et al. [27] \\
\hline China & 53 & 3 & 4 & 19 & UBT & Community & Rural & 1994 & Western Pacific & Ma et al. [28] \\
\hline India & 6 & 3 & 10 & 30 & Serology & Clinic & Urban & 1989 & Southeast Asia & Graham et al. [29] \\
\hline Japan & 12.5 & 1 & 4 & 56 & Serology & Clinic & Urban & 1994 & Western Pacific & Matsukura et al. [30] \\
\hline Korea & 6 & 1 & 3 & 52 & Serology & Clinic & Both & $1998^{j}$ & Western Pacific & Malaty et al. [31] \\
\hline Vietnam & 13 & 0 & 9 & 61 & Serology & Clinic & Urban & 1987 & Western Pacific & Megraud et al. [23] \\
\hline Belgium & 6.4 & 1 & 5 & $n / a^{e}$ & Serology & Clinic & Both & $1995^{j}$ & Europe & Blecker et al. [32] \\
\hline Estonia & 4.9 & 9 & 9 & 94 & Serology & Community & Both & 1993-1996 & Europe & Vorobja et al. [33] \\
\hline Finland & 6 & 3 & 3 & 131 & Serology & Community & Both & 1980 & Europe & Ashorn et al. [34] \\
\hline France & 4 & 0 & 9 & 113 & Serology & Clinic & Urban & 1987 & Europe & Megraud et al. [23] \\
\hline Germany & 8.3 & 3 & 5 & 36 & Serology & Clinic & Urban & 1984 & Europe & Hornemann et al. [35] \\
\hline Iceland & 9 & 0 & 9 & 13 & Serology & Clinic & Both & 1991-1992 & Europe & Bergenzaum et al. [36] \\
\hline Italy & 22 & 1 & 10 & 32 & Serology & Clinic & Urban & 1995 & Europe & Luzza et al. [37] \\
\hline Netherlands & 9 & 6 & 8 & 80 & Serology & Clinic & Urban & 1993 & Europe & Roosendaal et al. [38] \\
\hline Poland & 16.6 & 3 & 5 & 60 & Serology & Clinic & Urban & 1996 & Europe & Czkwianianc et al. [39] \\
\hline Portugal & 42.6 & 3 & 6 & $\mathrm{n} / \mathrm{a}^{\mathrm{e}}$ & Serology & Clinic & Urban & $1994^{j}$ & Europe & Quina et al. [40] \\
\hline Russia & 30 & 1 & 4 & 44 & Serology & Community & Urban & 1996 & Europe & Malaty et.al [41] \\
\hline Spain & 11 & 2 & 9 & 203 & Serology & Clinic & Both & 1991-1992 & Europe & Cilla et al. [42] \\
\hline Sweden & 7.7 & 1 & 4 & 661 & Serology & Clinic & Urban & 1984-1995 & Europe & Grandstorm et al. [43] \\
\hline Switzerland & 7 & 5 & 7 & 432 & UBT & Community & Both & 1998 & Europe & Boltshauser et al. [44] \\
\hline Australia & 25 & 2 & 4 & 20 & Serology & Clinic & Urban & 1991 & Western Pacific & Hardikar et al. [45] \\
\hline Gambia & 31 & 0 & 5 & 353 & Serology & Community & Rural & 1990 & Africa & Sullivan et al. [46] \\
\hline Singapore & 3 & 0 & 4 & 305 & Serology & Community & Urban & 1992 & Western Pacific & {$[17]$} \\
\hline Thailand & 74 & 1 & 4 & 27 & Serology & Community & Urban & 1990 & Southeast Asia & Perez-Perez et al. [18] \\
\hline
\end{tabular}

${ }^{\mathrm{a}} \mathrm{H}$. pylori prevalence (\%).

${ }^{\mathrm{b}}$ Minimum age of children in the studies.

${ }^{c}$ Maximum age of children in the studies.

d Number of children in the age group.

e Only the prevalence rate was available.

${ }^{f}$ Method of detection was either by serological assay using lgG (serology) or urea breath test (UBT).

9 Population source was either clinic-based or community-based.

h Studies were conducted in urban, rural or both areas.

'The year the $\mathrm{H}$. pylori study was done.

${ }^{\mathrm{j}}$ The year H. pylori study was published.

${ }^{k}$ World Health Organization region a country is situated.

$(\mathrm{n}=3)$ as the method of $H$. pylori detection. Out of the twenty-eight $H$. pylori studies, eighteen were clinic-based and ten were community-based surveys. Four studies were conducted in urban areas, and only eight studies were done in both settings. The average interval between the ALL incidence and the $H$. pylori surveys was 4.1 years. Half of the studies were conducted in Europe $(\mathrm{n}=14)$, four studies were from the Americas $(14.3 \%)$ and six were from Western Pacific (21.4\%). Only two studies were from Africa (7.1\%) and another two studies were from South-East Asia (7.1\%). The average GNP per capita for the countries was US\$11,375.79, while the average HDI for the countries was 0.80 . In addition it was noted that both the weighted ALL incidence rates for each country $(n=28)$ and the ALL incidence rates for all cancer registries $(n=127)$ were normally distributed.

Confounders which did not have any collinearity with each other were GNP per capita (continuous) and the 
Table 2 Descriptive statistics for characteristics of ALL incidence and H. pylori prevalence studies/countries

\begin{tabular}{|c|c|c|c|c|c|}
\hline ALL incidence rate (per 100,000 persons) & Mean & Median & s.d. $^{b}$ & Frequency & (\%) \\
\hline Weighted ALL incidence ${ }^{\text {a }}$ (28 countries) & 17.61 & 16.40 & 11.75 & - & - \\
\hline Non-weighted ALL incidence rate (127 cancer registries) & 21.68 & 21.25 & 12.62 & - & - \\
\hline \multicolumn{6}{|l|}{ Characteristics of included countries $(n=28)$} \\
\hline Gross National Product per capita for countries (USD\$) & 11375.79 & 9520.00 & 1182.10 & - & - \\
\hline Human Development Index for countries & 0.80 & 0.87 & 0.14 & - & - \\
\hline Population size for countries & 118137528 & 36416282 & 265588002 & - & - \\
\hline \multicolumn{6}{|l|}{ Characteristics of $H$. pylori studies $(n=28)$} \\
\hline H. pylori prevalence (\%) & 26.56 & 19.30 & 21.46 & - & - \\
\hline Minimum age of children (years) & 2.21 & 1.50 & 2.25 & - & - \\
\hline Maximum age of children (years) & 6.21 & 5.00 & 2.43 & - & - \\
\hline Interval between ALL incidence and H. pylori surveys (years) & 4.11 & 3.00 & 4.78 & - & - \\
\hline \multicolumn{6}{|l|}{ Method of H. pylori detection } \\
\hline Serological assays using lgG & - & - & - & 25 & 89.29 \\
\hline Urea breath test & - & - & - & 3 & 10.71 \\
\hline \multicolumn{6}{|l|}{ Population source } \\
\hline Community-based & - & - & - & 10 & 35.71 \\
\hline Clinic-based & - & - & - & 18 & 64.29 \\
\hline \multicolumn{6}{|l|}{ Level of urbanization } \\
\hline Rural & - & - & - & 4 & 14.29 \\
\hline Urban & - & - & - & 16 & 57.14 \\
\hline Both rural and urban & - & - & - & 8 & 28.57 \\
\hline \multicolumn{6}{|l|}{ Region } \\
\hline Africa & - & - & - & 2 & 7.14 \\
\hline Americas & - & - & - & 4 & 14.29 \\
\hline Southeast Asia & - & - & - & 2 & 7.14 \\
\hline Europe & - & - & - & 14 & 50.00 \\
\hline Western Pacific & - & - & - & 6 & 21.43 \\
\hline
\end{tabular}

a Weighted ALL incidence rate for each country was obtained using the inverse variance method.

b Standard deviation.

population source used in the $H$. pylori surveys (clinicbased or community-based samples). These were included in the further analyses.

There was a negative association between $H$. pylori prevalence and ALL incidence rates. This was nonsignificant when the weighted ALL incidence rates for each country were used in the model (parameter estimate $=-0.10$, standard error $=0.11$, p-value $=0.35$ ), However when the ALL incidence rates for all cancer registries were modelled this association became significant (parameter estimate $=-0.14$, standard error $=0.05$, $\mathrm{p}$-value $\left.=0.01, \mathrm{R}^{2}=0.0485\right)$.

There was a positive association between ALL incidence rates and both confounders - the population source in the $H$. pylori surveys and the GNP per capita. This association was non-significant for the weighted ALL incidence rates (the population source used in the $H$. pylori surveys: parameter estimate $=$
2.98, standard error $=4.69, \mathrm{p}$-value $=0.53$; GNP per capita: parameter estimate $=0.0001$, standard error $=$ 0.0002, p-value $=0.55$ ), but became significant when the ALL incidence rates for all cancer registries were included separately (the population source used in the $H$. pylori surveys: parameter estimate $=5.40$, standard error $=2.57$, $\mathrm{p}$-value $=0.04$; GNP per capita: parameter estimate $=0.0003$, standard error $=0.00009, \quad \mathrm{p}$-value $=$ 0.0004, $\left.\mathrm{R}^{2}=0.0953\right)$.

The effect of the association between the ALL incidence rates for all cancer registries and the $H$. pylori prevalence rates were attenuated (became non-significant) slightly when it was adjusted for the population source used in the $H$. pylori surveys (parameter estimate $=-0.11$, standard error $=0.06$, $\mathrm{p}$-value $=0.06)$. This attenuation was more pronounced when the analysis was adjusted for GNP per capita (parameter estimate = -0.05 , standard error $=0.06, \mathrm{p}$-value $=0.41)$ and changed 
further when the analysis was adjusted for both the population source used in the $H$. pylori surveys and GNP per capita (parameter estimate $=-0.02$, standard error $=0.07$, p-value $=0.82$ ).

Generalized Estimating Equations (GEE) [14] were used to assess the relationship between $H$. pylori prevalence and ALL incidence rates among the 127 cancer registries in the 28 countries, accounting for the repeated observations within countries. The results were similar to the associations found in both the unadjusted and adjusted linear regression analyses when the ALL incidence rate for all cancer registries were modelled. For example, the unadjusted analyses for the association between ALL incidence and $H$. pylori prevalence rates had a parameter estimate of -0.14 , standard error of 0.05 and $\mathrm{p}$-value of 0.01 using both methods.

\section{Conclusion}

Smith et al. [47] showed that improved hygiene, as measured by decreased prevalence of Hepatitis A virus, is associated with higher childhood ALL incidence rates. In our study we examined whether the level of sanitation, using $H$. pylori as the marker, is associated with incidence rates of childhood ALL in different countries. Our analyses demonstrated inverse association between $H$. pylori prevalence and ALL incidence rates in children. This implies that countries, where children live in better sanitary conditions and have lower $H$. pylori prevalence rates, are expected to experience increased childhood ALL incidence rates. However these associations were minor and only significant for ALL incidence rates for all cancer registries $(\mathrm{n}=127)$. These associations became non-significant and smaller in magnitude, when the population source and/or the GNP per capita were added to the relationship. Furthermore, these results were unchanged when the association were examined using the Generalised Estimating Equations. Therefore, although we showed that lower prevalence of $H$. pylori and improved sanitation is associated with increased incidence of childhood ALL, our findings do not conclusively support Greaves' [9] " delayed infection" hypothesis.

One of the strengths in our study is the use of $H$. pylori as a biomarker for sanitation. However, as ours was an ecological study, various weaknesses are associated with the study design [14]. One is ecologic bias. This means that even though inverse associations between $H$. pylori prevalence and incidence rates of childhood ALL among populations were shown, this cannot be translated into an increased risk of incidence of ALL in an individual child known to be infected by $H$. pylori. Doing so would be erroneous and leads to ecologic fallacy. Ecologic bias can arise as a result of biases within the group studied, confounding by groups or effect modification by groups [14]. There are also more problems in ecologic studies as compared to individual-level studies with regards to the selection, control and analysis of confounders [14]. This was experienced in our study. In addition, ecologic studies do not provide assurance that disease occurrence did not precede exposure [14]. Temporality is an important criterion that needs to be met for causality in an exposure-disease relationship. Collinearity is another limitation as certain predictors, such as socio-demographic and environmental factors, tend to be highly correlated with each other than they are at individual level [14]. This is illustrated in our study, for example, between the level of urbanization and GNP per capita. Ecologic studies are also limited by lack of adequate data or if available, these data may not be comparable [14]. This was certainly seen in our study as there were insufficient data on $H$. pylori prevalence and when available, they were not comparable due to the different methodologies used in the various H. pylori studies. Another limitation is ALL incidence, especially in developing countries, may actually be higher since ALL may not have been diagnosed and recorded for all cases.

In view of the numerous weaknesses associated with ecologic studies, future studies looking at the association between sanitation and the incidence of childhood ALL should be done employing individual-level study designs, such as case-control studies. This will be ideal as childhood ALL is a rare disease and sanitation and H. pylori are not rare exposures.

\section{Competing interests}

I declare no financial or non-financial competing interests in the submission of this manuscript.

\section{Author's contribution}

I performed all the steps involved in this study including the

conceptualisation, design, acquisition of data, analysis and interpretation, including the drafting and submission of this manuscript.

Received: 8 March 2012 Accepted: 18 June 2012

Published: 3 July 2012

\section{References}

1. In International Incidence of Childhood Cancer, Vol. II, IARC Scientific Publications, Volume 144. Edited by Parkin DM, Kramaírovaí E, Draper GJ, Masuyer E, Michaelis J, Neglia J, Qureshi S, Stiller CA. Lyon, France: International Agency on Research on Cancer; 1998.

2. Smith MA, Ries LAG, Gurney JG, Ross JA: Leukemia. In Cancer Incidence and Survival Among Children and Adolescents: United States SEER Program 1975 1995, NIH Publications, Volume no. 99 - 4649. Bethesda, Maryland: National Cancer Institute, Surveillance Epidemiology and End Results (SEER) Program; 1999.

3. Linet MS, Devesa SS: Descriptive epidemiology of childhood leukemia. $\mathrm{Br}$ J Cancer 1991, 63:424-429.

4. Greaves MF, Wiemels J: Origins of chromosome translocations in childhood leukemia. Nat Rev Cancer 2003, 3:639-649.

5. Greaves M: Childhood leukemia. Br Med J 2002, 324:283-287.

6. Greaves M: Molecular genetics, natural history and the demise of childhood leukemia. Eur J Cancer 1991, 35:173-185.

7. Greaves MF: Aetiology of acute leukemia. Lancet 1997, 349:344-349.

8. Ma X, Buffler PA, Selvin S, Matthay KK, Wiencke JK, Wiemels JL, Reynolds P: Daycare attendance and risk of childhood acute lymphoblastic leukemia. Br J Cancer 2002, 86:1419-1424.

9. Perrillat F, Clavel J, Auclerc MF, Baruchel A, Leverger G, Nelken B, Philippe N, Schaison G, Sommelet D, Vilmer E, Hemon D: Day-care, early common 
infections and childhood acute leukemia: a multicentre French casecontrol study. Br J Cancer 2002, 86:1064-1069.

10. Wills-Karp M, Santeliz J, Karp CL: The germless theory of allergic disease: revisiting the hygiene hypothesis. Nat Rev Immunol 2001, 1:69-75.

11. Go MF: Review article: natural history and epidemiology of Helicobacter pylori infection. Aliment Pharmacol Ther 2002, 16:3-15.

12. Brown LM: Helicobacter pylori: epidemiology and routes of transmission. Epidemiol Rev 2000, 22:283-297.

13. Parkin DM, Whelan SL, Ferlay J, Teppo L, Thomas DB (Eds): Cancer Incidence in Five Five Continents, Volume VIII. France: International Agency on Research on Cancer; 2002 (IARC Scientific Publications no. 155).

14. Rothman KJ, Greenland S (Eds): Modern Epidemiology. 2nd edition. Philadelphia: Lippincott-Raven; 1998.

15. Weiss NA: Introductory Statistics. 7th edition. Boston: Addison Wesley; 2004.

16. Torres J, Perez-Perez G, Goodman KJ, Atherton JC, Gold BD, Harris PR, la Garza AM, Guarner J, Munoz O: A comprehensive review of the natural history of Helicobacter pylori infection in children. Arch Med Res 2000, 31:431-469.

17. Committee on Epidemic Diseases, Ministry of Health, Singapore: Seroprevalence of $H$. pylori infection in Singapore. Epidemiol News Bull 1996, 22:31-32.

18. Perez-Perez Gl, Taylor DN, Bodhidatta L, Wongsrichanalai J, Baze WB, Dunn BE, Echeverria PD, Blaser MJ: Seroprevalence of Helicobacter pylori infections in Thailand. J Infect Dis 1990, 161:1237-1241.

19. Mittal SK, Mathew JL: Helicobacter pylori infection in children: a review. Trop Gastroenterol 2003, 24:106-115.

20. World Health Organization Regional Offices: Retrieved February 152010 from www.who.int.

21. Gross National Product per capita: Retrieved February 152010 from: www. worldbank.org.

22. Human Development Index: Retrieved February 152010 from: hdr.undp.org.

23. Megraud F, Brassens-Rabbe MP, Denis F, Belbouri A, Hoa DQ: Seroepidemiology of Campylobacter pylori infection in various populations. J Clin Microbiol 1989, 27:1870-1873.

24. Oliveira AM, Queiroz DM, Rocha GA, Mendes EN: Seroprevalence of Helicobacter pylori infection in children of low socioeconomic level in Belo Horizonte, Brazil. Am J Gastroenterol 1994, 89:2201-2204.

25. Goodman KJ, Correa P, Tengana Aux HJ, Ramirez H, DeLany JP, Guerrero Pepinosa O, Lopez Quinones M, Collazos Parra T: Helicobacter pylori infection in the Colombian Andes: a population-based study of transmission pathways. Am J Epidemio/ 1996, 144(3):290-299.

26. Sierra R, Munoz N, Pena AS, Biemond I, van Duijin W, Lamers CB, Teuchmann S, Hernandez S, Correa P: Antibodies to Helicobacter pylori and pepsinogen levels in children from Costa Rica: comparison of two areas with different risks for stomach cancer. Cancer Epidemiol Biomarkers Prev 1992, 1:449-454.

27. Elitsur Y, Short JP, Neace C: Prevalence of Helicobacter pylori infection in children from urban and rural West Virginia. Dig Dis Sci 1998, 43:773-778.

28. Ma JL, You WC, Gail MH, Zhang L, Blot WJ, Chang YS, Jiang J, Liu WD, Hu YR, Brown LM, Xu GW, Fraumeni JF Jr: Helicobacter pylori infection and mode of transmission in a population at high risk of stomach cancer. Int J Epidemiol 1998, 27:570-573.

29. Graham DY, Adam E, Reddy GT, Agarwal JP, Agarwal R, Evans DJ Jr, Malaty HM, Evans DG: Seroepidemiology of Helicobacter pylori infection in India. Comparison of developing and developed countries. Dig Dis Sci 1991, 36:1084-1088

30. Matsukura N, Onda M, Tokunaga A, Teramoto T, Fujita I, Okuda T, Yamashita K: Detection of serum IgG antibody against Helicobacter pylori from childhood in a Japanese population. J Gastroenterol 1994, 29:403-405

31. Malaty HM, Kim JG, Kim SD, Graham DY: Prevalence of Helicobacter pylori infection in Korean children: inverse relation to socioeconomic status despite a uniformly high prevalence in adults. Am J Epidemiol 1996, 143:257-262.

32. Blecker U, Lanciers S, Hauser B, Vandenplas Y: Helicobacter pylori positivity in Belgium. Acta Gastroenterol Belg 1995, 58:31-34.

33. Vorobjova T, Grunberg H, Oona M, Maaroos HI, Nilsson I, Wadstrom T, Covacci A, Uibo R: Seropositivity to Helicobacter pylori and CagA protein in schoolchildren of different ages living in urban and rural areas in Southern Estonia. Eur J Gastroenterol Hepatol 2000, 12:97-101.

34. Ashorn M, Maki M, Hallstrom M, Uhari M, Akerblom HK, Viikari J, Miettinen A: Helicobacter pylori infection in Finnish children and adolescents. A serologic cross-sectional and follow-up study. Scand J Gastroenterol 1995 30:876-879.

35. Hornemann F, Nilius M, Malfertheiner P, Bartmann P: Seroprevalence of Helicobacter pylori in German infants and children. Helicobacter 1997, 2:176-179.

36. Bergenzaun $P$, Kristinsson KG, Thjodleifsson $B$, Sigvaldadottir E, Molstad $S_{\text {, }}$ Held M, Wadstrom T: Seroprevalence of Helicobacter pylori in south Sweden and Iceland. Scand J Gastroenterol 1996, 31:1157-1161.

37. Luzza F, Imeneo M, Maletta M, Paluccio G, Giancotti A, Perticone F, Foca A Pallone F: Seroepidemiology of Helicobacter pylori infection and Hepatitis $A$ in a rural area: evidence against a common mode of transmission. Gut 1997, 41:164-168.

38. Roosendaal R, Kuipers EJ, Buitenwerf J, van Uffelen C, Meuwissen SG, van Kamp GJ, Vandenbroucke-Grauls CM: Helicobacter pylori and the birth cohort effect: evidence of a continuous decrease of infection rates in childhood. Am J Gastroentereol 1997, 92:1480-1482.

39. Czkwiamiamc E, Bak-Romaniszyn L, Malecka-Panas E, Suski S, Woch G: Prevalence of Helicobacter pylori in children dependently on age and living conditions. J Physiol Pharmacol 1996, 47:203-207.

40. Quina MG: Helicobacter pylori: the Portuguese scene. Grupo de Estudo Portugues do Helicobacter pylori (GEPHP). Eur J Cancer Prev 1994, 3(Suppl 2):65-67.

41. Malaty HM, Paykov V, Bykova O, Ross A, Graham DP, Anneger JF, Graham DY: Helicobacter pylori and socioeconomic factors in Russia. Helicobacter 1996, 1:82-87.

42. Cilla G, Perez-Trallero E, Garcia-Bengoechea M, Marimon JM, Arenas Jl: Helicobacter pylori infection: a seroepidemiology study in Gipuzkoa Basque County, Spain. Eur J Epidemiol 1997, 13:945-949.

43. Granstrom M, Tindberg Y, Blennow M: Seroepidemiology of Helicobacter pylori infection in a cohort of children monitored from 6 months to 11 years of age. J Microbiol 1997, 35:468-470.

44. Boltshauser S, Herzog D: Prevalence of Helicobacter pylori infection in asymptomatic 5 - 7-year old children of St. Gallen canton (German) Schweizerische Medizinische Wochenschrift. Schweiz Med Wschr. J Suisse de Med 1999, 129:579-584.

45. Hardikar W, Grimwood K: Prevalence of Helicobacter pylori infection in asymptomatic children. J Paediatr Child Health 1995, 31:537-541.

46. Sullivan PB, Thomas JE, Wight DG, Neale G, Eastham EJ, Corrah T, LloydEvans N, Greenwood BM: Helicobacter pylori in Gambian children with chronic diarrhoea and malnutrition. Arch Dis Child 1990, 65:189-191.

47. Smith MA, Simon R, Strickler HD, McQuillan G, Ries LA, Linet MS: Evidence that childhood acute lymphoblastic leukemia is associated with an infectious agent linked to hygiene conditions. Cancer Causes Control 1998, 9:285-298.

doi:10.1186/1756-0500-5-345

Cite this article as: Hishamuddin: The association between Acute Lymphoblastic Leukemia in children and Helicobacter pylori as the marker for sanitation. BMC Research Notes 2012 5:345.

\section{Submit your next manuscript to BioMed Central and take full advantage of:}

- Convenient online submission

- Thorough peer review

- No space constraints or color figure charges

- Immediate publication on acceptance

- Inclusion in PubMed, CAS, Scopus and Google Scholar

- Research which is freely available for redistribution

Submit your manuscript at www.biomedcentral.com/submit
C) Biomed Central 